\title{
Evaluation of Anti-Cancer Potential of Capsaicin-Loaded Trimethyl Chitosan-Based Nanoparticles in HepG2 Hepatocarcinoma Cells
}

Islam E Elkholi ${ }^{1}$, Noha M Hazem², Wagdi F ElKashef ${ }^{3}$, Mohamed A Sobh ${ }^{4}$, Dalia Shaalan ${ }^{2}$, Mohamed Sobh ${ }^{1}$ and Ibrahim M El-Sherbiny ${ }^{5 *}$

${ }^{1}$ Medical Experimental Research Center, Mansoura University, Mansoura ET-35516, Egypt

${ }^{2}$ Biochemistry Department, Faculty of Medicine, Mansoura University, Mansoura ET-35516, Egypt

${ }^{3}$ Pathology Department, Faculty of Medicine, Mansoura University, Egypt

${ }^{4}$ Experimental Biology Department, Urology and Nephrology Center, Mansoura University, Egypt

${ }^{5}$ Zewail City of Science and Technology, Center for Materials Science, 6th October City, 12588 Giza, Egypt

\begin{abstract}
Hepatocellular carcinoma $(\mathrm{HCC})$ is a highly aggressive malignancy characterized by its high resistance to chemotherapeutic agents leading to high morbidity and mortality rates. Capsaicin, the active ingredient of hot peppers, has been reported for its potential as an active anti-cancer agent. In this study, we hypothesized that incorporating capsaicin into nanocarriers might improve its pharmacokinetics. As a result, densely dispersed capsaicin-loaded trimethyl-chitosan nanoparticles (CL-NPs) were developed and their anti-tumor effect was investigated in comparison with capsaicin on human HepG2 cells. The CL-NPs were obtained via ionotropic gelation of cationic trimethyl chitosan (TMCS). Both synthesized TMCS and TMCS-based nanoparticles were characterized using zeta analyzer, nanosizer, and TEM. Human hepatoma cell line (HepG2) were cultured then divided into 4 groups receiving ethanol, conventional capsaicin, plain nanoparticles (PNs), or CL-NPs in dose of $100 \mu \mathrm{M}$. The apoptotic activity in the cell line was evaluated by DNA fragmentation assay, immunocytochemistry for caspase-3 and BCL-2, in addition to gene expression studies of BCL-2, and Bax genes via RT-PCR. The capsaicin effect on HCC response to chemotherapy was also assessed by studying the level of MDR-1 (multidrug resistance) gene expression. CL-NPs in dose of $100 \mu \mathrm{M}, 24 \mathrm{~h}$ after treatment, showed more upregulation of Bax and downregulation of both BCL-2 and MDR-1 genes in comparison with conventional capsaicin. In addition, immunocytochemistry assay revealed that both capsaicin and plain NPs show higher expression of caspase-3 and lower expression of BCL-2 than the control group, while the group treated with CL-NPs showed complete necrosis. This indicates that plain TMCS nanoparticles had a little anti-apoptotic effect by themselves. Our findings highlight the potential of the developed CL-NPs as an effective anti-cancer agent which efficiently induced apoptosis in human HepG2 hepatocarcinoma cells. Moreover, a possible role in improving response to chemotherapy has been observed through downregulation of MDR-1 gene.
\end{abstract}

Keywords: HCC; Capsaicin; Chitosan; Polymeric nanoparticles; Nano-capsaicin; MDR-1; Apoptosis

\section{Introduction}

Hepatocellular carcinoma (HCC) is considered as the third most common cause of cancer-related death worldwide [1]. Where, it accounts for over half a million deaths per year [2,3]. The high morbidity and mortality rates caused by HCC, is attributed to its chemoresistance. It has been proven that HCC displays high resistance to chemotherapeutic agents, such as adriamycin (ADM), cisplatin, 5-fluorouracil (5-FU) and doxorubicin $[4,5]$. The molecular mechanisms of drug resistance are complex and haven't been fully explored. Overexpression of multidrug resistance (MDR-1) gene is a major clinical hurdle for successful chemotherapy of HCC patients [6]. Multidrug resistance protein 1 (MDR1),also known as P-glycoprotein 1 (permeability glycoprotein) or ATP-binding cassette sub-family B member 1 (ABCB1), is an important protein of the cell membrane that pumps many foreign substances out of cells. It is an ATP-dependent efflux pump with broad substrate specificity. It is extensively distributed and expressed in liver cells where it pumps them into bile ducts [7]. Recently, it is proposed that MDR-1 gene expression of HCC could be modulated rendering the cancer cells more sensitive to chemotherapeutic agents [8].

Capsaicin (8-methyl N-Vanillyl-6 nonenamide) is the active component of hot peppers of the genus Capsicum [9]. Since its structure was first described by Nelson in 1919 [10], Capsaicin's physiological and pharmacological effects have been studied along the past decades. Capsaicin has been used in pain relief, weight reduction, in addition to cardiovascular effects as a vasodilator and anti-platelet aggregation, and dermatological inflammatory-associated diseases [11-18]. Moreover, the anti-cancer effect of capsaicin has been a hot area of research. In recent years, capsaicin has been used in suppressing the carcinogenicity of many types of tumors as: lung, prostate, breast, gastric, pancreatic, colorectal, and osteosarcoma [19-26].

In the last decade, studies [27-34] showed that capsaicin efficiently induced apoptosis in HCC cells. In spite of being studied more than once, there is no single clear mechanism by which capsaicin induced apoptosis in HCC. Jung et al. showed that capsaicin induced apoptosis through a caspase-3-dependant mechanism [27]. Other study showed that capsaicin induced apoptosis in human hepatoma HepG2 cells through increasing intracellular calcium and reactive oxygen species (ROS) [28]. Although it was stated that human hepatoma-derived cell types exhibit a major resistance to TRAIL-induced apoptosis [35-38], Moon et al. showed that capsaicin sensitizes HCC cells to TNF-related

*Corresponding author: Ibrahim M El-Sherbiny, Professor of Nanomaterials Science, Center for Materials Science, University of Science and Technology Zewail City of Science and Technology, 6th of October City, 12588 Giza, Egypt, Tel.: 2-0106-333-0913; E-mail: ielsherbiny@Zewailcity.edu.eg

Received October 17, 2014; Accepted November 05, 2014; Published November 15,2014

Citation: Elkholi IE, Hazem NM, ElKashef WF, Sobh MA, Shaalan D, et al. (2014) Evaluation of Anti-Cancer Potential of Capsaicin-Loaded Trimethyl Chitosan-Based Nanoparticles in HepG2 Hepatocarcinoma Cells. J Nanomed Nanotechnol 5: 240. doi: 10.4172/2157-7439.1000240

Copyright: ( 2014 Elkholi IE, et al. This is an open-access article distributed under the terms of the Creative Commons Attribution License, which permits unrestricted use, distribution, and reproduction in any medium, provided the original author and source are credited. 
Citation: Elkholi IE, Hazem NM, EIKashef WF, Sobh MA, Shaalan D, et al. (2014) Evaluation of Anti-Cancer Potential of Capsaicin-Loaded Trimethyl Chitosan-Based Nanoparticles in HepG2 Hepatocarcinoma Cells. J Nanomed Nanotechnol 5: 240. doi: 10.4172/2157-7439.1000240

Page 2 of 8

apoptosis-inducing ligand (TRAIL), which induces apoptosis through activating two distinct receptors, death receptor 4 (DR4) and DR5 [34].

In spite of all these uses and promising results as an anti-cancer agent, capsaicin has a low bioavailability hindering its systemic use. Capsaicin is a fat soluble substance with poor water solubility leading to short biological half-life [39]. However, no prior studies, reported the incorporation of capsaicin into a polymeric nano-carrier in order to increase its bioavailability. Incorporation of capsaicin into polymeric nano-carriers might improve its pharmacokinetics via increasing its water solubility, permeability through physiological barriers leading to improved biodistribution and therefore its bioavailability and therapeutic efficacy [40]. Moreover, the polymeric nano-carriers, either produced from natural or synthetic polymers, can be tailored to show desirable physicochemical characteristics. As a result, in this study, capsaicin-loaded TMCs (trimethyl chitosan) NPs (nanoparticles) were synthesized via ionotropic gelation of cationic TMCs in mild aqueous conditions. The TMCs has been synthesized through two-steps pathway. Firstly, dimethyl chitosan (DMCs) was obtained through formic acidformaldehyde methylation (Eschweiler-Clarke). Then, DMCs was converted into TMCs through reaction with methyl iodide. Finally, the densely dispersed plain and capsaicin-loaded nanoparticles were investigated as potential controlled release carriers. The anti-cancer potential of capsaicin on HCC and the effect of nanoparticles delivery on capsaicin efficacy have been in vitro investigated. Furthermore, the ability of capsaicin to modulate MDR gene expression was investigated.

\section{Materials and Methods}

\section{Materials used in preparing TMCs nanoparticles}

Chitosan (average $\mathrm{Mw}$ of $354,000 \mathrm{Da}$, as determined by viscosity measurements in a solvent of $0.1 \mathrm{M}$ acetic acid- $0.2 \mathrm{M} \mathrm{NaCl}$ maintained at $25^{\circ} \mathrm{C}$, and $\mathrm{N}$-deacetylation of $76.3 \%$, as measured by elemental analysis), formaldehyde (37\% stabilized with methanol), N-methyl 2-pyrrolidone (NMP), sodium triphosphate pentabasic (STPP) of practical grade 9095\%, and formic acid were provided by Sigma Aldrich (St. Louis, MO). Methyl iodide of purity $99 \%$ stabilized with copper was purchased from Acros Organics (Geel, Belgium). Hydrochloric acid, methanol, sodium hydroxide and all other chemicals were of analytical grade and used as received.

\section{Preparation of Trimethyl chitosan}

Trimethyl chitosan (TMCs) was prepared using two-step reaction pathway reported by Verheul et al. [41] after some modification. The first step involves the conversion of chitosan (Cs) into dimethyl chitosan (DMCs). In this step, a formic acid-formaldehyde methylation method (Eschweiler-Clarke) was applied to synthesize the DMCs. The formic acid was also used to dissolve the Cs molecules. In brief, $10 \mathrm{~g}$ of CS was transferred into a 0.5 liter round-bottom flask. Afterwards, $30 \mathrm{ml}$ of formic acid was added followed by $40 \mathrm{ml}$ of formaldehyde (37\%) and $180 \mathrm{ml}$ of distilled water. Then, the reaction mixture was refluxed at $70^{\circ} \mathrm{C}$ with stirring for 4 days. Afterwards, the viscous pale yellow solution was evaporated using rotary evaporator followed by dropwise addition of $1 \mathrm{M} \mathrm{NaOH}$ aqueous solution to increase the $\mathrm{pH}$ to 12 at which gel formation occurred. The resulting gel (DMCs) was washed with distilled water to remove any residuals followed by dissolving DMCs in distilled water at $\mathrm{pH} 4$ adjusted through dropwise addition of $1 \mathrm{M} \mathrm{HCl}$, filtered and dried. In the second step; DMCs has been converted into TMCs through reaction with methyl iodide in N-methyl 2-pyrrolidone (NMP) [41]. Briefly, $0.25 \mathrm{~g}$ of DMCs was dissolved in $35 \mathrm{ml}$ distilled water and the $\mathrm{pH}$ was adjusted to 11 through dropwise addition of 1
$\mathrm{M} \mathrm{NaOH}$ until gel formation. The gel was then washed with distilled water followed by two times with acetone. Afterwards, the DMCs was suspended in $50 \mathrm{ml} \mathrm{NMP}$ followed by addition of $2 \mathrm{ml}$ of methyl iodide. The dispersion was stirred for $20 \mathrm{~h}$ at $40^{\circ} \mathrm{C}$, and subsequently dropped in $100 \mathrm{ml}$ of (1:1) ethyl alcohol/diethyl ether mixture. The resulting TMCs was collected by centrifugation, washed with diethyl ether, and dried. The dried product was dissolved in $100 \mathrm{ml}$ of aqueous $\mathrm{NaCl}$ solution $(10 \% \mathrm{w} / \mathrm{v})$ with stirring for $20 \mathrm{~h}$ for ion-exchange. The product was then dialyzed against deionized water, filtered, dried at $45^{\circ} \mathrm{C}$ under vacuum and stored until further investigation.

\section{Preparation of the TMCs nanoparticles}

The TMCs NPs were prepared using ionotropic gelation technique. Typically, a predetermined weight of TMCs was dissolved in $0.03 \%$ $\mathrm{v} / \mathrm{v}$ acetic acid solution to produce $0.5 \% \mathrm{w} / \mathrm{v}$ cationic TMCs solution. Then, a predetermined volume of $0.2 \% \mathrm{w} / \mathrm{v}$ STPP aqueous solution was added dropwise to the TMCs with sonication using a sonication probe (Misonix ultrasonic processor, S-4000, MisonixInc, CT, USA) for $3 \mathrm{~min}$. The added STPP was $0.25 \% \mathrm{w} / \mathrm{w}$ relative to the TMCs. During sonication, opalescent suspension was formed spontaneously at room temperature which was further examined as the TMCs NPs. The capsaicin-loaded TMCs NPs were prepared using the same procedure but with incorporation of $15 \% \mathrm{w} / \mathrm{w}$ of the capsaicin.

\section{Instrumental analysis}

The particle size analysis and the surface charge of both the prepared plain TMCs NPs and capsaicin-loaded TMCs NPs were determined by Zetasizer particle analyzer ver. 7.01 (Malvern Instruments Ltd, UK), with a refractive index of 1.33 for the solvent. Prior to size analysis, all the samples were diluted with distilled water to suitable concentration. The morphology of the resulting TMCs NPs was investigated by transmission electron microscopy, TEM (JEOL TEM-1230) attached to a CCD camera at an accelerating voltage of $120 \mathrm{kV}$. The samples were prepared by placing few drops of the NPs suspension on carbon coated copper grids, followed by allowing the solvent to slowly evaporate before recording the TEM images. The approximate size of the NPs was also estimated from TEM micrographs.

\section{Cell line and culture conditions}

Human hepatocarcinoma (HepG2) cell lines were maintained at theMedical Experimental Research Center, Mansoura University. The cell culture medium was Dulbecco's modified Eagle's medium (DMEM) supplemented with 10\% fetal bovine serum (FBS), 100 units/ $\mathrm{ml}$ penicillin and $100 \mu \mathrm{g} / \mathrm{ml}$ streptomycin. The cells were cultured at $37^{\circ} \mathrm{C}$ under a humidified atmosphere containing $5 \% \mathrm{CO}_{2}$.

\section{Capsaicin administration}

Cells in a $75 \mathrm{~cm}^{2}$ tissue culture flask were treated with different concentration of capsaicin, plain TMCS NPs and capsaicin-loaded TMCS NPs. Each of capsaicin and plain TMCS NPs was dissolved in $70 \%$ ethanol at concentrations of $(1 \mathrm{M}$ and $5 \mathrm{mM})$ respectively as stock solutions which were then diluted with DMEM to desired concentrations of $(100,150,200$ and $250 \mu \mathrm{M})$ for $48 \mathrm{~h}$, and control with ethanol. Cells were washed with PBS and trypsinized for collecting different aliquots for studying immunocytochemistry and molecular DNA and Hematoxylin \& Eiosein stain.

\section{Analysis of cell viability}

Cell culture: HepG2 (human hepatoma) cells were harvested by trypsinization, plated $\left(5 \times 10^{4} \mathrm{cells} / \mathrm{ml}\right)$ in 96 -well cell culture plate 
Citation: Elkholi IE, Hazem NM, ElKashef WF, Sobh MA, Shaalan D, et al. (2014) Evaluation of Anti-Cancer Potential of Capsaicin-Loaded Trimethyl Chitosan-Based Nanoparticles in HepG2 Hepatocarcinoma Cells. J Nanomed Nanotechnol 5: 240. doi: 10.4172/2157-7439.1000240

Page 3 of 8

and maintained in Dulbecco's Modified Eagle Medium (DMEM) for $48 \mathrm{~h}$ at $37^{\circ} \mathrm{C}$ in $95 \%$ air and $5 \% \mathrm{CO}_{2}$ atmosphere, with $95 \%$ humidity. Cultures were exposed only to medium (ethanol, controls) or medium containing different concentrations of capsaicin, TMCS plain NPs and capsaicin-loaded TMCS NPs dissolved in ethanol. Each of capsaicin and plain TMCS NPs was dissolved in $70 \%$ ethanol at concentrations of $(1 \mathrm{M}$ and $5 \mathrm{mM})$ respectively as stock solutions which were then diluted with DMEM to desired concentrations of $(100,150,200$ and $250 \mu \mathrm{M})$ for $48 \mathrm{~h}$, and control with ethanol. At the end of this incubation period, cells were briefly washed with Phosphate-buffered saline (PBS). Fresh medium $(100 \mu \mathrm{l})$ was then placed in each well and MTT (3-(4,5-Dimethylthiazol-2-yl)-2,5-diphenyltetrazolium bromide) assays performed as described below.

Overall cell activity - MTT assay: Effect on overall cell activity was determined by performing the MTT assay based on the method of Oka et al., [42]. The MTT assay measures the metabolism of 3-(4, 5-dimethylthiazol-2yl) -2, 5 - biphenyl tetrazolium bromide to form an insoluble formazan precipitate by mitochondrial dehydrogenases only present in viable cells. After exposure of cells to different concentrations of capsaicin, plain TMCS NPs and capsaicin-loaded TMCS NPsfor 48 $\mathrm{h}$, one hundred $(100 \mu \mathrm{l})$ microlitres of MTT $(1 \mathrm{mg} / \mathrm{mL})$ solution was added to each well of the 96 -well plate, and the plate was incubated at $37^{\circ} \mathrm{C}$ for $2 \mathrm{~h}$. The medium was then removed by aspiration. Finally, $100 \mu \mathrm{l}$ DMSO was added per well, the plate was shaken for a further 30 min and the absorbance at $520 \mathrm{~nm}$ with a $650 \mathrm{~nm}$ reference wavelength was measured using a microplate reader EL x 800 Universal Microplate Reader, (BIO-TEK INSTRUMENTS, USA) and the percentage of cytotoxicity compared to the untreated cells was determined with the equationgiven below. A plot of \% cytotoxicity versus sample concentrations was used to calculate the concentration which showed $50 \%$ cytotoxicity (IC50).

Cytotoxicity $(\%)=[100 \times($ Absorbance of untreated groupAbsorbance of treated group]/Absorbance of untreated group

DNA fragmentation assay: According to Moon et al., [34]; 100 $\mu$ l of lysis buffer containing $10 \mathrm{mM}$ Tris ( $\mathrm{pH} 7.4$ ), $150 \mathrm{mMNaCl}, 5 \mathrm{mM}$ EDTA and $0.5 \%$ Triton X-100 was used for cell lysis for $30 \mathrm{~min}$ on ice. Lysates were vortexed and centrifuged at $10,000 \times \mathrm{g}$ for $20 \mathrm{~min}$. Fragmented DNA in the supernatant was extracted with an equal volume of phenol/chloroform/isoamylalcohol mixture (25:24:1) and analyzed electrophoretically on $1.5 \%$ agarose gels containing $0.1 \mu \mathrm{g} / \mathrm{ml}$ ethidium bromide.

Immunocytochemistry for caspase-3 and BCL-2: Cell suspensions of 500 cells $/ \mathrm{mm}^{3}(\mu \mathrm{l})$ with PBS were prepared. Then cytospin prepared coated slides were prepared and fixed immediately in $95 \%$ ethanol. The slides were rinsed $3 \times 5 \mathrm{~min}$ with PBS to remove fixative. Endogenous

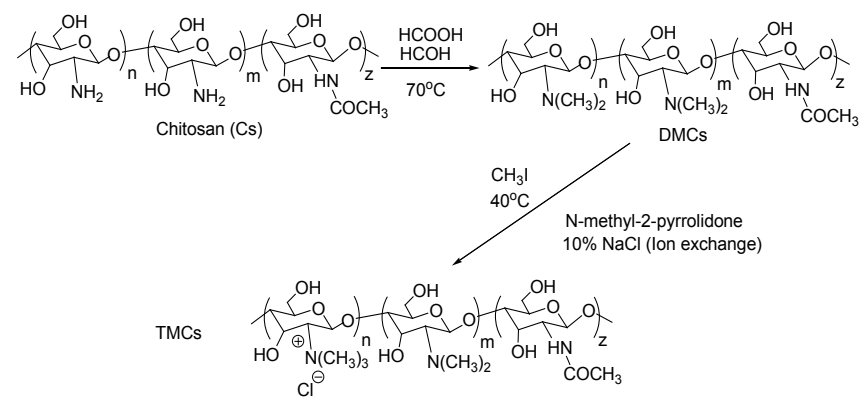

Scheme 1: The two-steps synthesis of TMCs. peroxidase was blocked by Hydrogen Peroxide Block for 10-15 minutes (Thermo Fisher Scientific, CA, USA) then washed 4 times in PBS. Nonspecific protein binding was then blocked by Ultra V Block (Thermo Fisher Scientific, CA, USA) for $10 \mathrm{~min}$ at room temperature. The slides were incubated with a rabbit antihuman caspase-3 \& BCL2 antibodies (NeoMarker, CA, USA) for 60 minutes. Slides were then treated with UltraVision ONE HRP Polymer detection system (Thermo Fisher Scientific, CA, USA) for $30 \mathrm{~min}$ at room temperature; washed 4 times in PBS followed by application of diaminobenzidine (DAB) solution until color developed. The tissue sections were then counterstained with haematoxylin and mounted.

Assessment of prepared slides for caspase-3 \& BCL-2: Caspase-3 \& BCL-2 were expressed as cytoplasmic brown color of hepatocytes. The assessment includes determination of intensity of the staining and the number of stained cells by high power field.

Assay of expression of Bcl-2 mRNA, Bax mRNA (apoptotic markers), and MDR -1 gene mRNA by total RNA extraction and RTPCR: Total RNA Extraction: Total RNA was extracted using the TriFast reagent (Peqlab, Germany). Reverse transcription reaction was done by using QuantiTect ${ }^{\mathbb{B}}$ Reverse Transcription Kit (Qiagen). After following the protocol instructions, the reaction mixure was incubated $15 \mathrm{~min}$ at $42^{\circ} \mathrm{C}$. Then, the reaction was terminated by heating at $95^{\circ} \mathrm{C}$ for 3 min. cDNA products were used for PCR. Specific gene primers used were Forward 5-CGACGACTTCTCCCGCCGCTACCGC-3 and Reverse 5-CCGCATGCTGGGGCCGTACAGTTCC-3 corresponding to a 319bp region of Bcl-2, Forward 5-AGACAGGGGCCCTTTTGCTTC-3 and Reverse 5-CCCCAGTTGAAGTTGCCGTC-3 corresponding to a 262-bp region of Bax, Forward 5'-AAGCTTAGTACCAAAGAGGCTCTG-3' and Reverse 5'-GGCTAGAAACAATAGTGAAAACAA-3' corresponding to a 243bp region of MDR-1 and Forward 5-GACCTGACTGACTACCTCATGA-3 and Reverse 5- TGATCTCCTTCTGCATCCTGTC-3 corresponding to a 402-bp region of B-actin. PCR was done by adding $25 \mu \mathrm{l}$ of DreamTaq ${ }^{\mathrm{Tm}}$ Green PCR Master Mix (2X) (Fermentas Life Sciences, U.S.A) to $5 \mu \mathrm{l}$ template cDNA , $1.0 \mu \mathrm{M}$ forward primer, $1.0 \mu \mathrm{M}$ reverse primer, and nuclease free water up to $50 \mu \mathrm{l}$. Initial denaturation was done for $5 \mathrm{~min}$ at $95^{\circ} \mathrm{C}$. The cycling conditions ( 40 cycles) were as following: (a) $30 \mathrm{~s}$ at $95^{\circ} \mathrm{C}$, (b) $30 \mathrm{~s}$ at $58^{\circ} \mathrm{C}$ for Bax and MDR- 1 and $30 \mathrm{~s}$ at $60^{\circ} \mathrm{C}$ for Bcl-2 and $\mathrm{B}$-actin, and (c) $1 \mathrm{~min}$ at $72^{\circ} \mathrm{C}$ with a subsequent 7 min extension at $72^{\circ} \mathrm{C}$. The reaction products were analyzed on $1.5 \%$ agarose gels. Ethidium bromide was used to visualize the bands.

\section{Results}

\section{Formation of TMCs NPs}

In the present study, densely dispersed plain and capsaicin-loaded NPs were developed and investigated as potential controlled release carriers for efficient cancer treatment. The NPs were obtained via ionotropic gelation of cationic TMCs in mild aqueous conditions. The TMCs has been synthesized through two-steps pathway (Scheme 1). Firstly, DMCs was obtained through formic acid-formaldehyde methylation (Eschweiler-Clarke). Then, DMCs was converted into TMCs through reaction with methyl iodide.

The diameters of the developed plain and capsaicin-loaded TMCs NPs were found to be $77.3 \pm 18.7 \mathrm{~nm}$ and $294.3 \pm 53.3 \mathrm{~nm}$, respectively as determined by Malvern Zetasizer particle analyzer as shown in Figure 1. This size of the prepared plain and capsaicin-loaded TMCs NPs was also confirmed from the TEM analysis.

The zeta potential of the plain and capsaicin-loaded TMCs NPs was found to be 42.1 and $32.2 \mathrm{mV}$, respectively as illustrated in Figure 2 . 

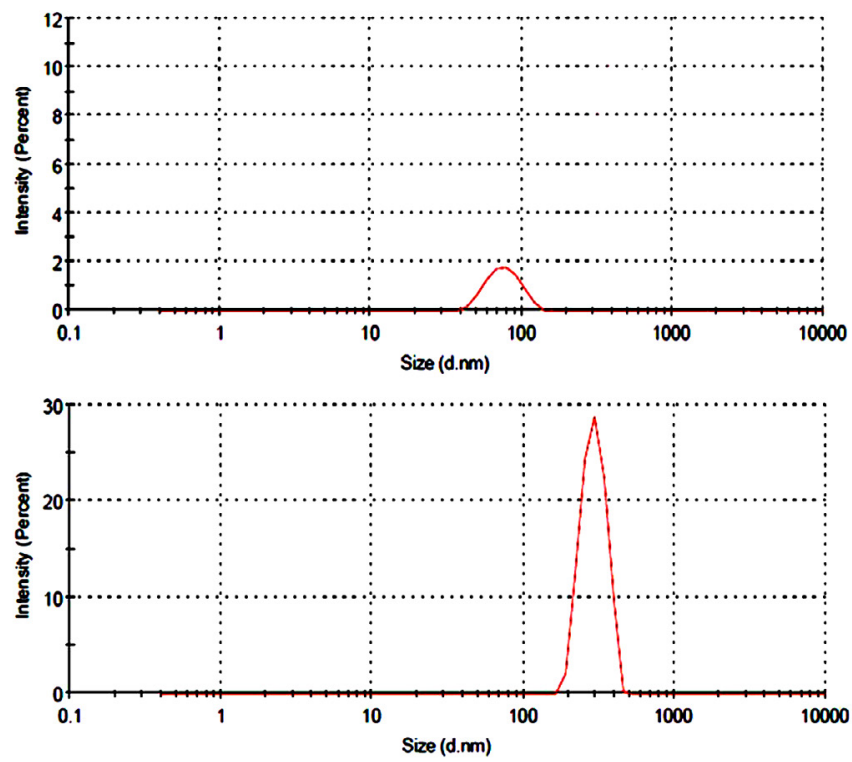

Figure 1: Particle size analysis of plain TMCs NPs (upper), and capsaicinloaded TMCs NPs (lower).
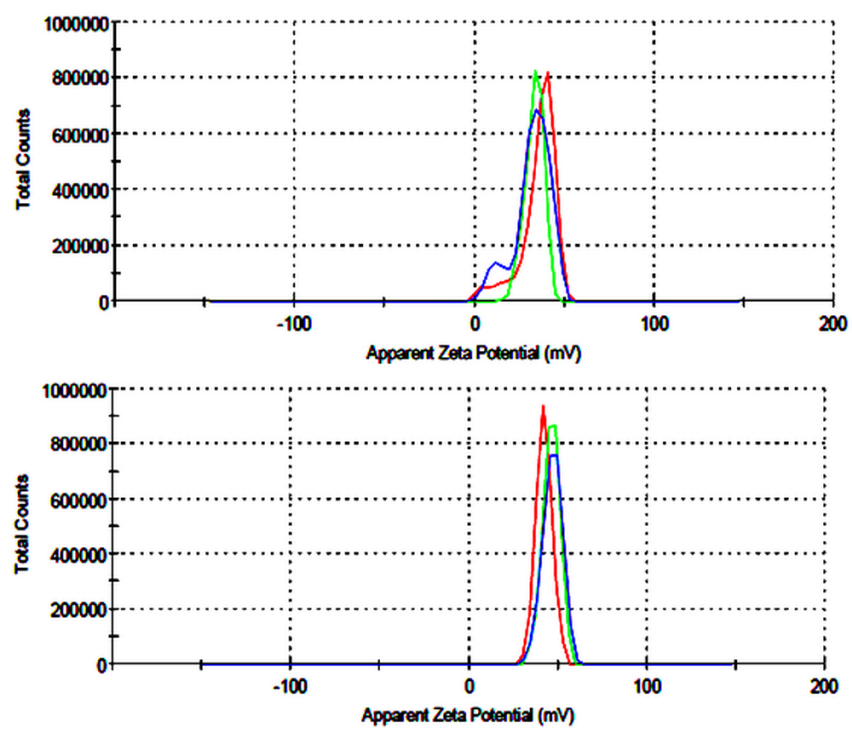

Figure 2: The zeta potential distribution of plain TMCs NPs (upper), and capsaicin-loaded TMCs NPs (lower).

These high zeta potential values $(>30 \mathrm{mV})$ in both plain and capsaicinloaded NPs are desirable as they indicate presence of electric repulsion between NPs and consequently prevent particles' aggregation.

Figure 3 demonstrates the transmission electron micrographs (TEM) of both plain and capsaicin-loaded NPs. As apparent from the figure, it is evident that the developed nanoparticles demonstrated almost spherical, dense, and integrated structure with an average diameter between $77.3 \pm 18.7 \mathrm{~nm}$ and $294.3 \pm 53.3 \mathrm{~nm}$ according to their composition.

\section{Overall cell activity - MTT assay}

To examine and compare the effects of capsaicin and capsaicin- loaded TMCS NPs on the growth of HepG2 hepatocellular carcinoma cells, a dose response MTT study was conducted. Treatment with capsaicin for $48 \mathrm{~h}$ inhibited growth of HepG2 cells in a concentrationdependent manner. It is calculated IC50 value was approximately 54.5 $\mu \mathrm{M}$. Nano-capsaicin was found to be much more potent inhibitor for HepG2 cells growth with IC50 value equals $0.48 \mu \mathrm{M}$. The plain TMCS NPs showed a growth inhibitory effect (IC50 value equals $160.06 \mu \mathrm{M}$ ) (Figure 4).

\section{DNA fragmentation assay}

DNA fragmentation assay was carried out to determine the mechanism of growth inhibition in HepG2 cells. It was found that HepG2 cells showed DNA fragmentation pattern, a characteristic of apoptosis, after treatment with capsaicin and capsaicin-loaded NPs at concentration of $100 \mu \mathrm{M}$ for $72 \mathrm{~h}$ and $24 \mathrm{~h}$ respectively. Difference between capsaicin and capsaicin-loaded NPs is poorly defined. In addition, plain NPs showed some DNA fragmentation activity. These results demonstrate that capsaicin and capsaicin-loaded NPs induced apoptosis in HepG2 hepatocellular carcinoma cells (Figure 5).

\section{Immunocytochemistry for apoptotic and anti-apoptotic markers (caspase-3 and BCL-2)}

Immunocytochemistry assay showed that, in comparison with the control group, treatment with either plain nanoparticles or capsaicin lead to reduction of the anti-apoptotic activity of the cancerous cells through decreasing the expression of BCL-2, in addition to increasing
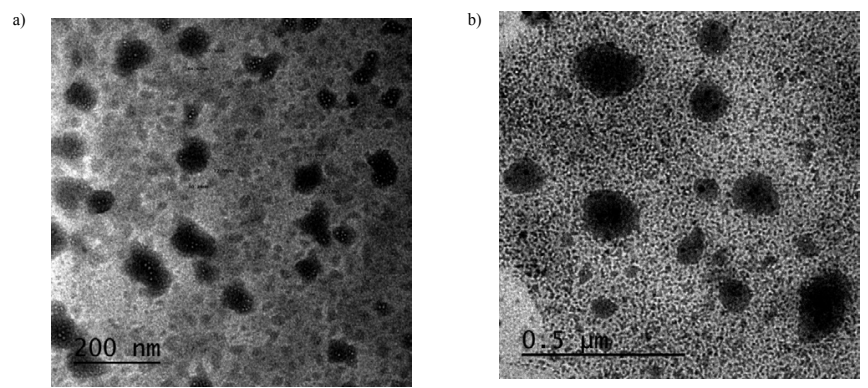

Figure 3: Transmission electron micrographs of (a) plain TMCs NPs, and (b) the capsaicin-loaded TMCs NPs.

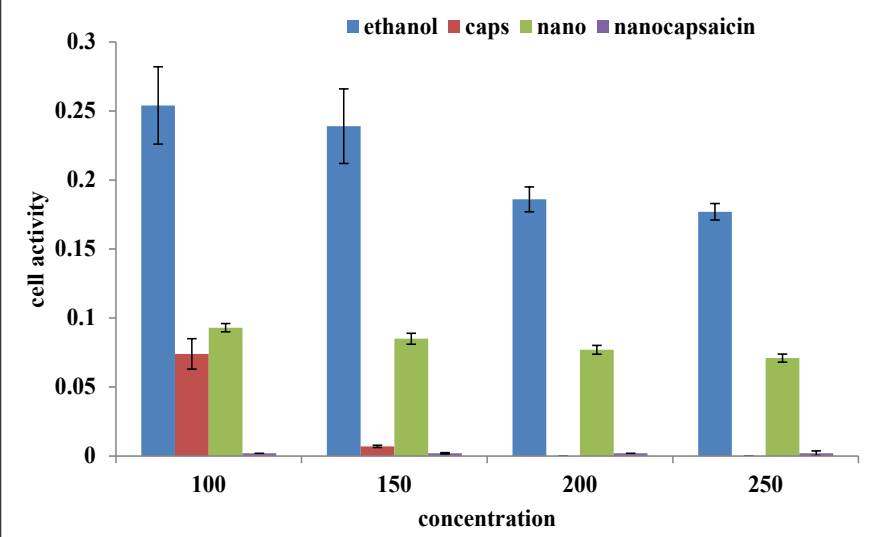

Figure 4: Effects of capsaicin (caps), plain NPs (nano) and capsaicin-loaded NPs (nanocapsaicin) (100-250 $\mu \mathrm{M})$ on viability of HepG2 cells after $48 \mathrm{~h}$. HepG2 viability was measured by MTT assay. Results are shown as mean \pm SEM, derived from at least $n=4$ replicates. 
Citation: Elkholi IE, Hazem NM, ElKashef WF, Sobh MA, Shaalan D, et al. (2014) Evaluation of Anti-Cancer Potential of Capsaicin-Loaded Trimethyl Chitosan-Based Nanoparticles in HepG2 Hepatocarcinoma Cells. J Nanomed Nanotechnol 5: 240. doi: 10.4172/2157-7439.1000240

Page 5 of 8

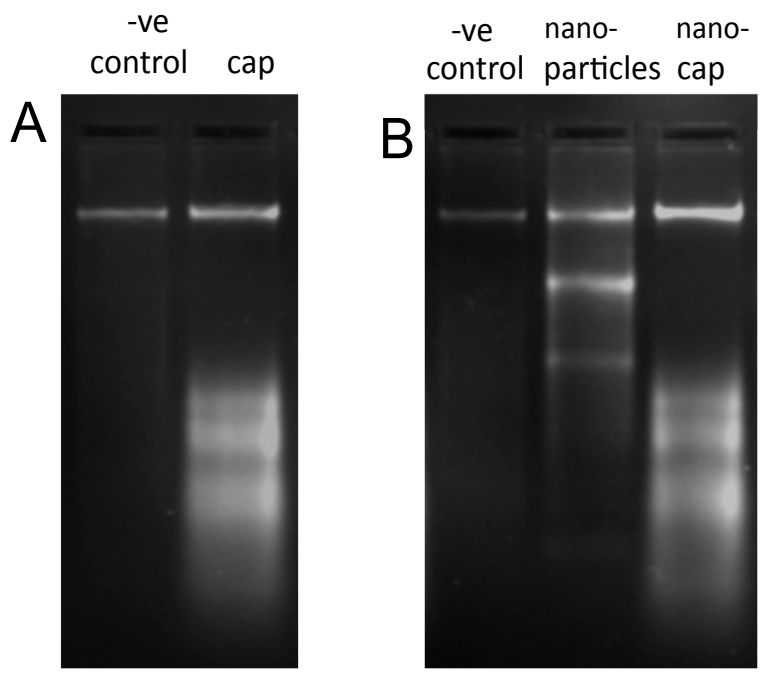

Figure 5: DNA fragmentation pattern in HepG2 cells treated with (A) $100 \mu \mathrm{M}$ capsaicin for $72 \mathrm{~h}$; (B) $100 \mu \mathrm{M}$ capsaicin-loaded NPs (nanocapsaicin) for 24 $\mathrm{h}$. The extracted DNA was analyzed electrophoretically on $1.5 \%$ agarose gel.

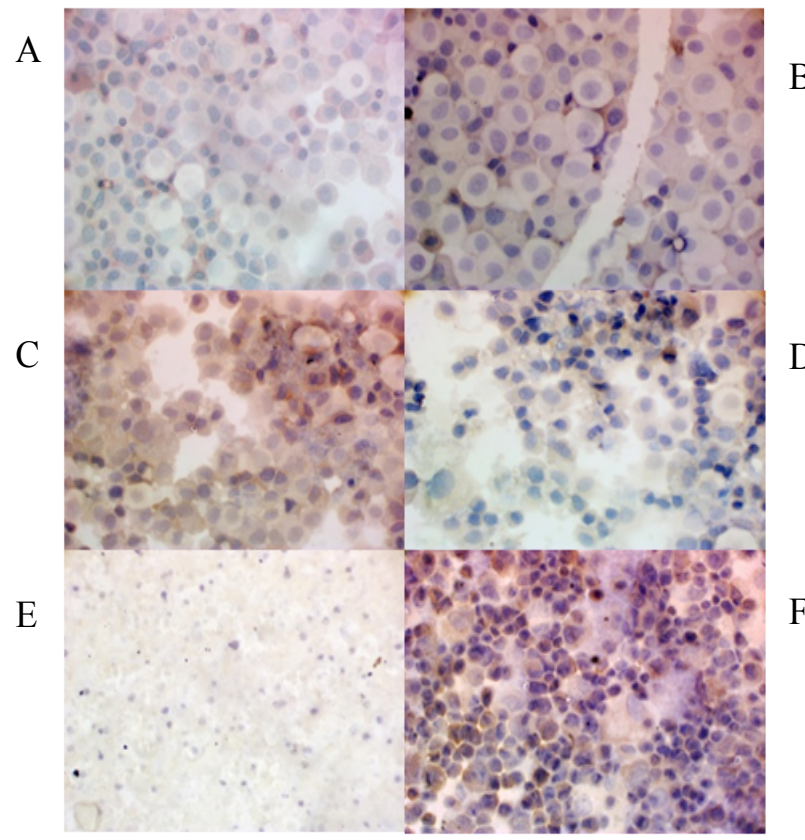

Figure 6: (A) Capsaicin group showing mild positive cytoplasmic reaction in $6 / 100$ tumor cells (BCL-2 IHC, 400x). (B) Capsaicin group showing mild positive cytoplasmic reaction in 5/100 tumor cells (Caspase IHC, 400x). (C) Plain NPs group showing mild positive cytoplasmic reaction in 2/100 tumor cells (BCL-2 IHC, 400x). (D) Plain NPs group showing mild positive cytoplasmic reaction in $3 / 100$ tumor cells (Caspase IHC, 400x). (E) Nano-capsaicin (CL-NPs) group showing necrosis $(400 \mathrm{x})$. (F) Control group showing moderate positive cytoplasmic reaction in about 10/100 of the tumor cells (BCL-2 IHC, 400x).

the apoptotic activity which is showed by higher expression of caspase- 3 . While, treatment with capsaicin-loaded NPs caused necrosis (Figure 6).

\section{Gene expression studies}

Bcl-2 and Bax genes expression: Gene expression studies were done to confirm apoptosis induction in HepG2 cells by capsaicin and capsaicin-loaded NPs and explain the underlying molecular mechanisms.Bcl-2 and Bax genes expression was investigated by RTPCR. HepG2 cells treated with $100 \mu \mathrm{M}$ capsaicin for $72 \mathrm{~h}$ showed decreased expression of the anti-apoptotic gene Bcl-2 whereas the expression of the death-promoting gene Bax was upregulated. Capsaicin-loaded NPs (100 $\mu \mathrm{M}$ for $24 \mathrm{~h})$ also down regulated Bcl-2, but not to a much more extent than capsaicin. Upregulation of Bax by capsaicin-loaded NPs was markedly higher than that caused by capsaicin (Figures 7 and 8).
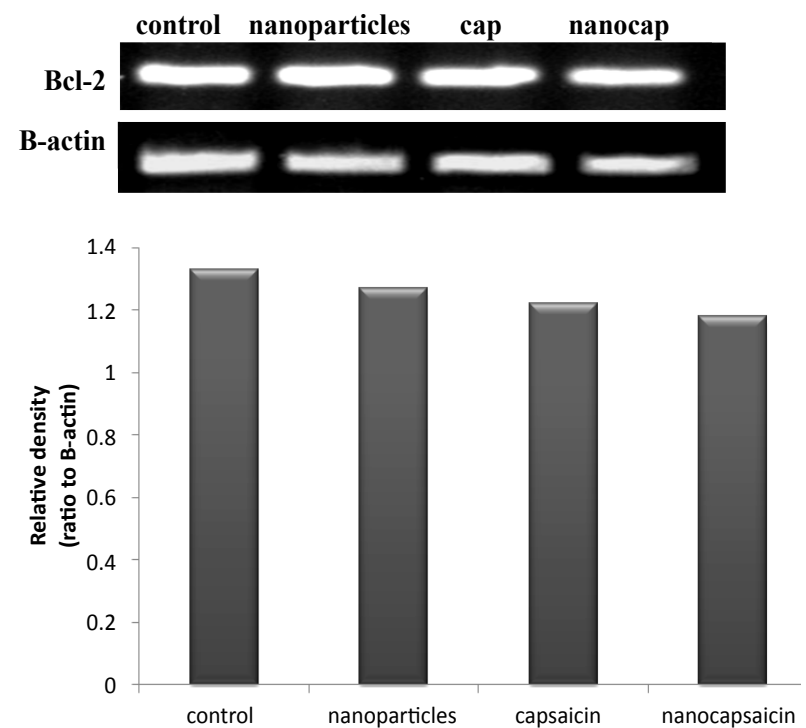

Figure 7: Capsaicin (cap) and capsaicin-loaded NPs (nano-capsaicin) inhibited Bcl-2 transcription. HepG2 cells treated with $100 \mu \mathrm{M}$ capsaicin for 72 $\mathrm{h}$ and $100 \mu \mathrm{M}$ capsaicin-loaded NPs for $24 \mathrm{~h}$. Total RNA was isolated, and RT-PCR analyses of $\mathrm{Bcl}-2$ and $\mathrm{B}$-actin were performed. Relative band density was quantified and plotted.
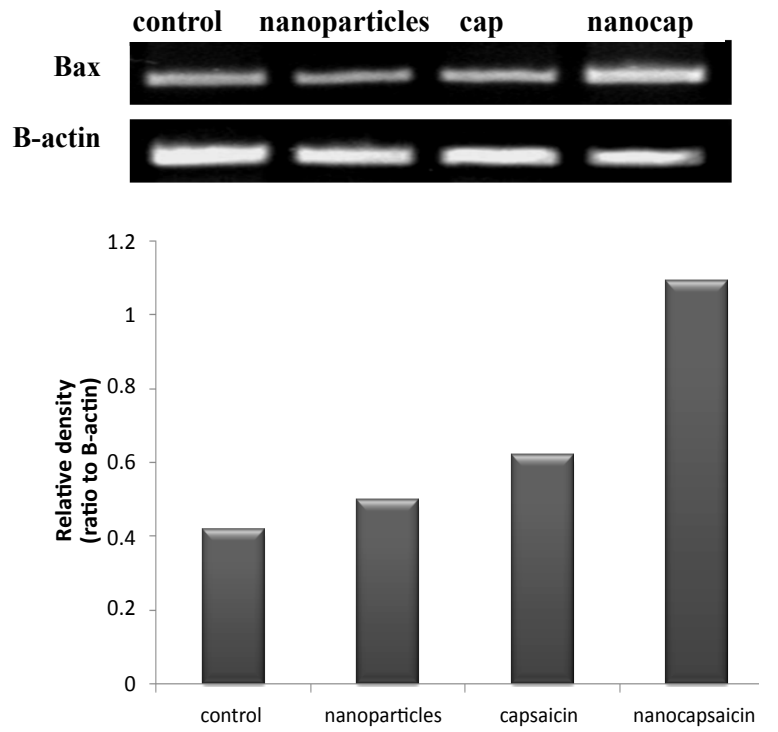

Figure 8: Capsaicin (cap) and CL-NPs (nanocap) activate Bax transcription. HepG2 cells treated with $100 \mu \mathrm{M}$ capsaicin for $72 \mathrm{~h}$ and $100 \mu \mathrm{M}$ capsaicinloaded NPs for $24 \mathrm{~h}$. Total RNA was isolated, and RT-PCR analyses of Bax and $\mathrm{B}$-actin were performed. Relative band density was quantified and plotted. 

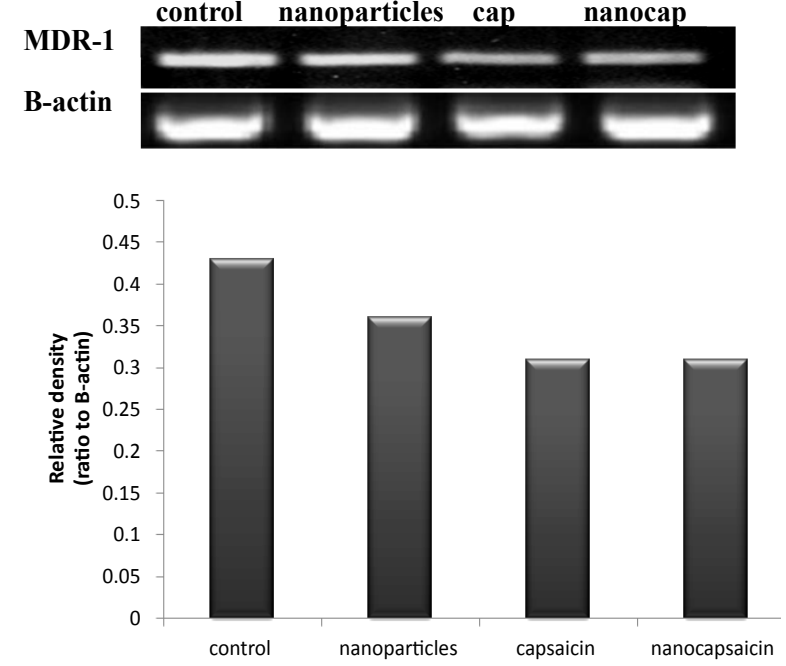

Figure 9: Downregulation of MDR-1 transcription by capsaicin (cap) and CLNPs (nanocapsaicin).HepG2 cells treated with $100 \mu \mathrm{M}$ capsaicin for $72 \mathrm{~h}$ and $100 \mu \mathrm{M}$ nanocapsaicin for $24 \mathrm{~h}$. Total RNA was isolated, and RT-PCR analyses of MDR-1 and B-actin were performed. Relative band density was quantified and plotted.

MDR-1 gene expression: MDR-1 gene expression was evaluated by RT-PCR to investigate if capsaicin and nano-capsaicin (CL-NPs) could modulate the response to the available chemotherapeutic agents. There was down-regulation of MDR-1 gene expression in HepG2 cells treated with either $100 \mathrm{uM}$ capsaicin for $72 \mathrm{~h}$ or $100 \mu \mathrm{M}$ capsaicin-loaded NPs for $24 \mathrm{~h}$. The extent of reduction in MDR-1 gene expression was nearly the same by both capsaicin and capsaicin-loaded NPs (Figure 9).

\section{Discussion}

Recently, chemopreventive approach against malignant cells in different organs has gained much more attention. Previous studies reported potential chemoprevention of capsaicin against hepatocarcinoma cell lines. The aim of this study was to evaluate the chemopreventive effect of capsaicin in comparison with capsaicinloaded TMCS NPs, both against HepG2 hepatocarcinoma cells.

The results of this study showed that capsaicin potentially inhibited HepG2 hepatocarcinoma cells proliferation with an IC50 value of approximately $54.5 \mu \mathrm{M}$. These results are in accordance with other studies which reported that capsaicin induced decreased cell viability and apoptosis in a dose- and time-dependent manner in HepG2 cells [28,33]. Also, Moon et al., [34] suggested that capsaicin induced a modest level of cell death HepG2 cells. Other study demonstrated that treatment of capsaicin for $72 \mathrm{~h}$ inhibited growth of SK-Hep-1 cells in a concentration-dependent manner, with an IC50 value of approximately $90 \mu \mathrm{M}$ [27]. Previous results evidenced that the features of these cell death induced by capsaicin were caused by apoptosis $[31,43,44]$.

In this study, the growth inhibition was more markedly observed in HepG2 hepatocarcinoma cells treated with nano-capsaicin that had an IC50 value of about $0.48 \mu \mathrm{M}$. These results suggesting that capsaicin as well as capsaicin-loaded NPs could trigger growth inhibition in HepG2 hepatocarcinoma cells. However, capsaicin-loaded NPs have much more potential to inhibit proliferation. This could be explained by alteration in properties of capsaicin after it had been formulated into nanocapsaicin.
Moreover, our results demonstrate that anti-proliferative property of capsaicin and nano-capsaicin $(100 \mu \mathrm{M})$ is principally due to apoptosis induction as evidenced by the characteristic apoptotic DNA fragmentation pattern that was relatively no more prominent in cells treated with nano-capsaicin. Previous study reported that capsaicin induced internucleosomal degradation of DNA, a characteristic of apoptosis. Treatment with $200 \mu \mathrm{M}$ capsaicin induced nucleosomal DNA fragmentation in SK-Hep-1 cells [27].

Apoptosis starts by translocation of cytochrome c, a respiratory chain protein, from mitochondria to cytoplasm where it activates Caspase- 3 which triggers the first proteolytic events of apoptosis $[45,46]$. Furthermore, disturbance in the balance between Bcl-2, antiapoptotic protein, and Bax, pro-apoptotic protein, contributes strongly to apoptosis induction. Bcl-2 prevents activation of caspase by blocking release of cytochrome $\mathrm{c}$ from mitochondria and thus leads to apoptosis inhibition. On the other hand, Bax enhances apoptosis by accelerating the pro-apoptotic events through inhibition of Bcl-2 action [46,47]. Both Bax protein and its mRNA levels were up-regulated in cells undergoing apoptosis [48]. Moreover, Bax overexpression has been demonstrated to accelerate apoptotic cell death $[49,50]$.

In this study, results show that capsaicin and nano-capsaicin decreased expression of $\mathrm{Bcl}-2$ and markedly increased expression of Bax. This may explain apoptosis induction in HepG2 cells by capsaicin and nano-capsaicin. Our results correlate well with that reported by Huang et al. [28] in which capsaicin significantly increased the level of Bax protein, while the Bcl-2 protein levels were decreased after the cells were treated with 100 or $200 \mu \mathrm{M}$ capsaicin. Macho et al. [51] demonstrated that Bcl-2 overexpression prevented capsaicin induced apoptosis although they did not observe any major change in the expression of Bcl-2 upon capsaicin treatment. In this study, nanocapsaicin has an augmented effect on both Bcl-2 and Bax expression than capsaicin. This difference in effect between capsaicin and nanocapsaicin was more prominent on Bax expression suggesting that nano-capsaicin is acting more strongly to induce apoptosis in HepG2 cells. Induction of apoptosis is confirmed by the results of immunocytochemistry which showed that capsaicin and plain TMCS nanoparticles lead to both decrease of the anti-apoptotic activity of the HepG2 cells through decreasing the expression of BCL-2 and increase the apoptotic activity by higher expression of caspase- 3 .

High resistance rate of HCC to chemotherapeutic agents represents a major medical problem. Multidrug resistance gene (MDR-1) overexpression has been claimed for unsuccessful chemotherapy of HCC [6]. Overexpression of MDR1 has been reported in some cell lines derived from human hepatocellular carcinomas (HCC) and hepatoblastomas (HB) [52]. Moreover, it has been identified that MDR1 gene product, P-glycoprotein, functions as energy-dependent efflux pumps to reduce intracellular drug levels [7]. In this study, the effects of capsaicin and nano-capsaicin on MDR expression were investigated and the results observed were very promising. MDR gene expression was reduced by both capsaicin and nano-capsaicin in HepG2 cells. However, nano-capsaicin has nearly similar reducing effect to that of capsaicin. These results suggested that capsaicin and nano-capsaicin could modify the level of MDR gene expression, and thus hepatocarcinoma cell response to chemotherapy may be improved.

From the previously mentioned results of this study, capsaicin and nanocapsaicin show a chemopreventive action against HepG2 hepatocarcinoma cells as both could induce apoptosis in these cells. Nanocapsaicin (CL-NPs) was more efficient than capsaicin in altering biological and molecular features of HepG2 cells including 
Citation: Elkholi IE, Hazem NM, ElKashef WF, Sobh MA, Shaalan D, et al. (2014) Evaluation of Anti-Cancer Potential of Capsaicin-Loaded Trimethyl Chitosan-Based Nanoparticles in HepG2 Hepatocarcinoma Cells. J Nanomed Nanotechnol 5: 240. doi: 10.4172/2157-7439.1000240

Page 7 of 8

growth inhibition, downregulation of $\mathrm{Bcl}-2$ and upregulation of Bax. Furthermore, capsaicin and nano-capsaicin were effective in downregulating MDR suggesting for a possible role in improving response to chemotherapy and raising the cure rate of hepatocellular carcinoma. The relative higher potency of nanocapsaicin observed in this study could be due to differences in properties between capsaicin and its incorporation into the polymeric trimethyl-chitosan nanoparticles. Limitation of these results is caused by the small sample size. Further research is needed on a larger sample size to compare the structure-bioactivity relationship between capsaicin and nanocapsaicin on HCC. This could contribute to the discovery of a new method for the treatment of liver cancer that may overcome drawbacks in the currently available therapies.

\section{References}

1. Graf D, Vallböhmer D, Knoefel WT, Kröpil P, Antoch G, et al. (2014) Multimoda treatment of hepatocellular carcinoma. Eur J Intern Med 25: 430-437.

2. Parkin DM, Bray FI, Devesa SS (2001) Cancer burden in the year 2000. The global picture. Eur J Cancer 37 Suppl 8: S4-66.

3. Kirk GD, Bah E, Montesano R (2006) Molecular epidemiology of human liver cancer: insights into etiology, pathogenesis and prevention from The Gambia, West Africa. Carcinogenesis 27: 2070-2082.

4. Li L, Wei XH, Pan YP, Li HC, Yang H, et al. (2010) LAPTM4B: a novel cancerassociated gene motivates multidrug resistance through efflux and activating PI3K/AKT signaling. Oncogene 29: 5785-5795

5. Wang XQ, Ongkeko WM, Chen L, Yang ZF, Lu P, et al. (2010) Octamer 4 (Oct4) mediates chemotherapeutic drug resistance in liver cancer cells through a potential Oct4-AKT-ATP-binding cassette G2 pathway. Hepatology 52: 528539.

6. Tsang WP, Kwok TT (2007) Riboregulator H19 induction of MDR1-associated drug resistance in human hepatocellular carcinoma cells. Oncogene 26: 4877 4881.

7. Aller SG, Yu J, Ward A, Weng Y, Chittaboina S, et al. (2009) Structure of P-glycoprotein reveals a molecular basis for poly-specific drug binding. Science 323: 1718-1722.

8. Xu Y, Xia F, Ma L, Shan J, Shen J, et al. (2011) MicroRNA-122 sensitizes HCC cancer cells to adriamycin and vincristine through modulating expression of MDR and inducing cell cycle arrest. Cancer Lett 310: 160-169.

9. Tominack RL, Spyker DA (1987) Capsicum and capsaicin--a review: case report of the use of hot peppers in child abuse. J Toxicol Clin Toxicol 25: 591-601.

10. Nelson EK (1919) The constitution of capsaicin, the pungent principle of capsicum. J Am Chem Soc 41: 1115-1121.

11. Biro T, Acs G, Acs P, Modarres S, Blumberg PM (1997) Recent advances in understanding of vanilloid receptors: a therapeutic target for treatment of pain and inflammation in skin. J Investig Dermatol Symp Proc 2: 56-60.

12. Caterina MJ, Schumacher MA, Tominaga M, Rosen TA, Levine JD, et al. (1997) The capsaicin receptor: a heat-activated ion channel in the pain pathway. Nature 389: 816-824

13. Maihofner C, Heskamp ML (2013) Prospective, non-interventional study on the tolerability and analgesic effectiveness over 12 weeks after a single application of capsaicin $8 \%$ cutaneous patch in 1044 patients with peripheral neuropathic pain: first results of the QUEPP study. Curr Med Res Opin 29: 673-683.

14. Lee GR, Shin MK, Yoon DJ, Kim AR, Yu R, et al. (2013) Topical application of capsaicin reduces visceral adipose fat by affecting adipokine levels in high-fat diet-induced obese mice. Obesity (Silver Spring) 21: 115-122.

15. Chen Q, Zhu H, Zhang Y, Zhang Y, Wang L, et al. (2013) [Vasodilating effect of capsaicin on rat mesenteric artery and its mechanism]. Zhejiang Da Xue Xue Bao Yi Xue Ban 42: 177-183.

16. Adams MJ, Ahuja KD, Geraghty DP (2009) Effect of capsaicin and dihydrocapsaicin on in vitro blood coagulation and platelet aggregation. Thromb Res 124: 721-723.

17. Mittelstadt SW, Nelson RA, Daanen JF, King AJ, Kort ME, et al. (2012) Capsaicin-induced inhibition of platelet aggregation is not mediated by transient receptor potential vanilloid type 1. Blood Coagul Fibrinolysis 23: 94-97.
18. Sekine R, Satoh T, Takaoka A, Saeki K, Yokozeki H (2012) Anti pruritic effects of topical crotamiton, capsaicin, and a corticosteroid on pruritogen-induced scratching behavior. Exp Dermatol 21: 201-204.

19. Anandakumar P, Kamaraj S, Jagan S, Ramakrishnan G, Devaki T (2013) Capsaicin provokes apoptosis and restricts benzo(a)pyrene induced lung tumorigenesis in Swiss albino mice. Int Immunopharmacol 17: 254-259.

20. Mori A, Lehmann S, O’Kelly J, Kumagai T, Desmond JC, et al. (2006) Capsaicin a component of red peppers, inhibits the growth of androgen-independent, p53 mutant prostate cancer cells. Cancer Res 66: 3222-3229.

21. Chou CC, Wu YC, Wang YF, Chou MJ, Kuo SJ, et al. (2009) Capsaicin-induced apoptosis in human breast cancer MCF-7 cells through caspase-independent pathway. Oncol Rep 21: 665-671.

22. Chow J, Norng M, Zhang J, Chai J (2007) TRPV6 mediates capsaicin-induced apoptosis in gastric cancer cells--Mechanisms behind a possible new "hot" cancer treatment. Biochim Biophys Acta 1773: 565-576.

23. Zhang R, Humphreys I, Sahu RP, Shi Y, Srivastava SK (2008) In vitro and in vivo induction of apoptosis by capsaicin in pancreatic cancer cells is mediated through ROS generation and mitochondrial death pathway. Apoptosis 13 1465-1478.

24. Skrzypski M, Sassek M, Abdelmessih S, Mergler S, Grötzinger C, et al. (2014) Capsaicin induces cytotoxicity in pancreatic neuroendocrine tumor cells via mitochondrial action. Cell Signal 26: 41-48.

25. Lee SH, Richardson RL, Dashwood RH, Baek SJ (2012) Capsaicin represses transcriptional activity of $\hat{I}^{2}$-catenin in human colorectal cancer cells. J Nutr Biochem 23: 646-655.

26. Chien CS, Ma KH, Lee HS, Liu PS, Li YH, et al. (2013) Dual effect of capsaicin on cell death in human osteosarcoma G292 cells. Eur J Pharmacol 718: 350360

27. Jung MY, Kang HJ, Moon A (2001) Capsaicin-induced apoptosis in SK-Hep-1 hepatocarcinoma cells involves $\mathrm{Bcl}-2$ downregulation and caspase- 3 activation. Cancer Lett 165: 139-145.

28. Huang SP, Chen JC, Wu CC, Chen CT, Tang NY, et al. (2009) Capsaicininduced apoptosis in human hepatoma HepG2 cells. Anticancer Res 29: 165174

29. Galati G, O'Brien PJ (2003) Cytoprotective and anticancer properties of coenzyme $Q$ versus capsaicin. Biofactors 18: 195-205.

30. Vriens J, Janssens A, Prenen J, Nilius B, Wondergem R (2004) TRPV channels and modulation by hepatocyte growth factor/scatter factor in human hepatoblastoma (HepG2) cells. Cell Calcium 36: 19-28.

31. Lee YS, Kang YS, Lee JS, Nicolova S, Kim JA (2004) Involvement of NADPH oxidase-mediated generation of reactive oxygen species in the apototic cell death by capsaicin in HepG2 human hepatoma cells. Free Radic Res 38: 405 412

32. Joung EJ, Li MH, Lee HG, Somparn N, Jung YS, et al. (2007) Capsaicin induces heme oxygenase-1 expression in HepG2 cells via activation of PI3KNrf2 signaling: $\mathrm{NAD}(\mathrm{P}) \mathrm{H}$ :quinone oxidoreductase as a potential target. Antioxid Redox Signal 9: 2087-2098.

33. Baek YM, Hwang HJ, Kim SW, Hwang HS, Lee SH, et al. (2008) A comparative proteomic analysis for capsaicin-induced apoptosis between human hepatocarcinoma (HepG2) and human neuroblastoma (SK-N-SH) cells. Proteomics 8: 4748-4767.

34. Moon DO, Kang CH, Kang SH, Choi YH, Hyun JW, et al. (2012) Capsaicin sensitizes TRAIL-induced apoptosis through Sp1-mediated DR5 up-regulation: involvement of $\mathrm{Ca}(2+)$ influx. Toxicol Appl Pharmacol 259: 87-95.

35. Ganten TM, Koschny R, Haas TL, Sykora J, Li-Weber M, et al. (2005) Proteasome inhibition sensitizes hepatocellular carcinoma cells, but not human hepatocytes, to TRAIL. Hepatology 42: 588-597.

36. Shigeno M, Nakao K, Ichikawa T, Suzuki K, Kawakami A, et al. (2003) Interferonalpha sensitizes human hepatoma cells to TRAIL-induced apoptosis through DR5 upregulation and NF-kappa B inactivation. Oncogene 22: 1653-1662.

37. Wirth T, Kühnel F, Fleischmann-Mundt B, Woller N, Djojosubroto M, et al. (2005) Telomerase-dependent virotherapy overcomes resistance of hepatocellular carcinomas against chemotherapy and tumor necrosis factor-related apoptosisinducing ligand by elimination of Mcl-1. Cancer Res 65: 7393-7402. 
Citation: Elkholi IE, Hazem NM, ElKashef WF, Sobh MA, Shaalan D, et al. (2014) Evaluation of Anti-Cancer Potential of Capsaicin-Loaded Trimethyl Chitosan-Based Nanoparticles in HepG2 Hepatocarcinoma Cells. J Nanomed Nanotechnol 5: 240. doi: 10.4172/2157-7439.1000240

Page 8 of 8

38. Yamanaka T, Shiraki K, Sugimoto K, Ito T, Fujikawa K, et al. (2000) Chemotherapeutic agents augment TRAlL-induced apoptosis in human hepatocellular carcinoma cell lines. Hepatology 32: 482-490.

39. Kasting GB (2001) Kinetics of finite dose absorption through skin 1. Vanillylnonanamide. J Pharm Sci 90: 202-212.

40. Trubetskoy VS (1999) Polymeric micelles as carriers of diagnostic agents. Adv Drug Deliv Rev 37: 81-88.

41. Verheul RJ, Amidi M, van der Wal S, van Riet E, Jiskoot W, et al. (2008) Synthesis, characterization and in vitro biological properties of O-methyl free $\mathrm{N}, \mathrm{N}, \mathrm{N}$-trimethylated chitosan. Biomaterials 29: 3642-3649.

42. Oka M, Maeda S, Koga N, Kato K, Saito T (1992) A modified colorimetric MTT assay adapted for primary cultured hepatocytes: application to proliferation and cytotoxicity assays. Biosci Biotechnol Biochem 56: 1472-1473.

43. Kim JA, Kang YS, Lee YS (2005) A phospholipase C-dependent intracellular $\mathrm{Ca} 2+$ release pathway mediates the capsaicin-induced apoptosis in HepG2 human hepatoma cells. Arch Pharm Res 28: 73-80.

44. Lee YS, Kwon EJ, Jin DQ, Park SH, Kang YS,et al.(2002) Redox statusdependent regulation of cyclooxygenases mediates the capsaicin-induced apoptosis in human neuroblastoma cells. J Environ Pathol Toxicol Oncol 21: 113-120.

45. Chauhan D, Pandey P, Ogata A, Teoh G, Krett N, et al. (1997) Cytochrome C-dependent and -independent induction of apoptosis in multiple myeloma cells. J Biol Chem 272: 29995-29997.
46. Kluck RM, Bossy-Wetzel E, Green DR, Newmeyer DD (1997) The release of cytochrome $\mathrm{c}$ from mitochondria: a primary site for $\mathrm{Bcl}-2$ regulation of apoptosis. Science 275: 1132-1136

47. Yang J, Liu X, Bhalla K, Kim CN, Ibrado AM, et al. (1997) Prevention of apoptosis by $\mathrm{Bcl}-2$ : release of cytochrome $\mathrm{c}$ from mitochondria blocked. Science 275: 1129-1132.

48. Yin XM, Oltvai ZN, Korsmeyer SJ (1994) BH1 and BH2 domains of Bcl-2 are required for inhibition of apoptosis and heterodimerization with Bax. Nature 369: 321-323.

49. Cooper JD, Michaelidis TM, Tzimagiorgis GZ, Sendtner M, Meyer M, et al. (1996) Cholinergic neuron-specific overexpression of Bax in ChATBax transgenic mice. Soc Neurosci Abstr 22: 570.

50. Kobayashi T, Ruan S, Clodi K, Kliche KO, Shiku H, et al. (1998) Overexpression of Bax gene sensitizes K562 erythroleukemia cells to apoptosis induced by selective chemotherapeutic agents. Oncogene 16: 1587-1591.

51. Macho A, Blázquez MV, Navas P, Muñoz E (1998) Induction of apoptosis by vanilloid compounds does not require de novo gene transcription and activator protein 1 activity. Cell Growth Differ 9: 277-286.

52. Minemura M, Tanimura H, Tabor E (1999) Overexpression of multidrug resistance genes MDR1 and cMOAT in human hepatocellular carcinoma and hepatoblastoma cell lines. Int J Oncol 15: 559-563. 